appearance, in this instance the rear being brought up by the halt and lame : crippled birds that have lost a greater or less number of their wing or tail feathers, some toes, or even a whole foot.

All this is very strikingly exemplified here by the blackbird, for instance, with its varying dress according to age and sex, and this might with some attention be observed at other places also, though in the middle and south of England and Germany such observations become greatly more complicated, on account of the immigrants from the north mixing with such of the same species as have been breeding in these more southern latitudes, and where the grand opening migratory rush, as witnessed here in full original purity, has more or less relaxed in a con amore travelling by easy stages.

Heligoland, May 7

\section{THE U.S. NATIONAL ACADEMY}

$\mathrm{NE}$ of the chief scientific events of the year in the United States is the annual meeting of the National Academy of Sciences, the most select scientific body in America, election to which is regarded as stamping a man as an acknowledged leader in science. This year the meeting took place at Washington from April $\mathrm{I} 5$ to $\mathrm{I} 8$, the acting president being Prof. O. C. Marsh, who opened the proceedings with a review of the Academy's official work during the previous year. $\mathrm{He}$ had to record the great loss sustained by the Academy in the death of its president, Prof. Joseph Henry, on May 13 last year. Henry had been president of the Acaderny for ten years. One of the principal functions of the Academy during the past year was the consideration of a plan for the reorganisation of the U.S. Surveys, to which we have already referred at length.

At the meeting of the Academy in April last year a resolution was adopted authorising the appointment of a committee to consider a plan proposed by Prof. Newcomb for determining the distance of the sun by measuring the velocity of light. In accordance with this vote, Prof Marsh appointed as members of the committee, President F. A. P. Barnard, Professors Wolcott Gibbs, Henry Morton, George F. Barker, and E. C. Pickering. Their report was so favourable to the plan proposed that Prof. Marsh sent it to the Secretary of the Navy for transmission to Congress. An appropriation of 5,000 dols. for the required purpose was thus secured, and the work of constructing the necessary apparatus will be commenced as soon as the appropriation is available. The expenditure of the funds is entrusted to the Secretary of the Navy. It is hoped by those who proposed this plan that the experiments will lead to a more accurate determination of the distance of the sun than can be obtained by any other method known to astronomy.

Prof. William B. Rogers was elected President of the Academy, to fill the vacancy caused by the death of Prof. Henry. The election is a deserved tribute to Prof. Rogers, who has for half a century held a prominent place among American men of science. He was for many years a leader among American geologists in adopting the modern theories of evolution, and defended his views with rare eloquence as well as strong argument. During his connection with the Massachusetts Institute of Technology (1862-68), the health of Prof. Rogers became sø much impaired that he was obliged to withdraw from all studious pursuits for a long period. His recovery of health was the occasion of hearty congratulation in 1875 , when he was for a second time elected President of the American Association for the Advancement of Science. The new president is loved by everybody, is venerable with silver locks, and still retains the silver-tongued eloquence for which he used to be famous. But he is by no means rugged, and has to take care not to over-exert himself.

Many valvable papers were read during the meeting of the Academy, but our space will only permit of our referring to a few. We append a complete list, and those who desire a complete report of the Academy's proceedings will find it in Science Neres of May $I$ and following numbers.

Two papers were presented by $\mathrm{Mr}$. Peirce, entitled respec. tively, "On Ghosts in Diffraction Spectra" and "Comparison of Wave-Lengths with the Metre." It is well known to users of diffraction spectroscopes that ghosts of the lines appear in the images. Mr. Peirce has investigated this subject from a mathematical point of view, and he presented to the Academy a series of calculations based on the conditions which call forth these ghosts, and concluding with formulæ for determining their positions. In conjunction with Mr. Rutherfurd, Mr. Peirce has been investigating the relation of the wave-lengths of light to the metre. The object is to obtain a basis for measuring the standard metre. The metres that have been issued as standards change in length after a lapse of time. The German metre is said to differ from the French metre by one 25,000 th. Mr. Peirce proceeded on the assumption that the wave-lengths of light are of a constant value. Certain questions have arisen in the course of this research. It was necessary to ascertain whether the spectral lines were fine enough to serve the purpose. There was a doubt as to whether the lines were displaced by "ghosts," and this led to the mathematical inquiry, previously alluded to, which has defined the position of ghosts relatively to the lines. Again, it was found needful that the spectrum to be observed should be at its maximum of brilliance. It had been noticed that two spectra composing a pair (that is, of the same order) are usually of different brightness, the right side spectrum differing from the left side one. This was specially true of spectra obtained from ruled glass; those from speculum metal were not so notably diverse in brightness. Examination showed that this characteristic was due to a difference in the sides of the groove ruled in glass. The diamond, in ploughing through the surface, raises a burr on the side of the furrow, and hence makes the two sides of the cut of unequal height. At first it was attempted to remove this imperfection by rubbing off the burr ; bat it was found that the material of the burr went to fill up the groove, and thus rendered the glass plate unserviceable. But, by first filling the groove with black-lead, then polishing off the burr, and finally removing the black-lead, plates were obtained that gave spectra of the utmost brilliancy, and the right and left spectra of each pair did not differ in brightness from each other. Mr. Peirce also gave the particulars of other improvements recently made in spectroscopic apparatus. One of these involved the construction of glass circles, and the work was so delicate that a well-known instrument maker had failed in four attempts. A method was described by which the accurate focussing of the heliostat-a matter of great importance-had been satisfactorily attained. The experimenters have succeeded in measuring a number of decimetre scales by centimetres. The probability of a single error is within the fiftieth part of a micron. (A micron is as much smaller than a millimetre as the latter is less than a metre.) Means have been devised which keep the apartment, where the experiments are made, at a fixed temperature, within one-tenth of a degree of Fahrenheit. With a sufficient number of observations, and the use of apparatus having their latest improvements, these experimenters hope to attain the object of their research, and limit the error to one-millionth part of a wavelength.

Prof. E. C. Pickering's paper on eclipses of Jupiter's satêllites was one of considerable importance. He showed the value of the photometric method of observing these eclipses, and the valuable data that might be obtained by improvements in this method, both as to the sun's distance and as to Jupiter himself and his satellites.

In a paper on the winds on Mount Washington compared with the winds near the level of the sea, Prof. Elias Loomis came to the following conclusions:-I. In a majority of the cases where an area of low barometer passes over New England, attended by the usual circulating winds at the surface stations, this system of circulating winds does not extend to a height of 6,000 feet. 2. This system of circulating winds extends to the greatest height when the depression of the barometer is unusually great. 3. When, during the progress of an area of low pressure, a system of circulating winds reaches to the summit of Mount Washington, the change of wind to the east quarter usually begins at the surface stations eleven hours sooner than on the summit of the mountain; and the change back from east 
to west usually begins five hours sooner at the base than at the summit.

Prof. Joseph Le Conte's paper on the extinct volcanoes about Lake Mono, and their relation to the glacial drift, was of much interest. The general form of the Sierra is that of a great wave, ready to break on its eastern side. It rises from the San Joaquin Plains by a gentle slope of fifty to sixty miles, reaches a crest 13,000 feet high, and then, in a space of five or six miles, plunges downward steeply to the plains of Mono, which are at an altitude of only 6,00o feet. In former periods, long, complicated glaciers, with many tributaries, occupied the western slope; on the east, comparatively short and simple glaciers came down in parallel streams, and stretched far out on the plain and into Lake Mono, which was then 700 feet above its present level, and of far greater extent than now, so that it washed the base of the Sierra. Icebergs from the glaciers floated on this inland sea and dropped débris on its bottom. Around the present lake is a nearly level desert plain, covered with volcanic sand, interspersed with fragments of pumice and obsidian, and overgrown with sage-brush (Artemisia tridentata). This plane is an old lake bottom; the volcanic ashes are a later deposit upon it. The desert is relieved by the Sierra walls, with deep cañons; by long parallel moraine ridges, stretching like arms from the mouth of each cañon, and bounding the pathways of ancient glaciers; by a cluster of recently extinct volcanic cones, fifteen or twenty in number; and, finally, by the bright waters and picturesque islands of the lake. The moraines average 300 to 406 feet in height, and five or six miles in length. Lake Mono is ten by fourteen miles in extent. Having no outlet, its waters are saline-essentially a strong solution of sodium carbonate, with smaller proportions of calcic carbonate, common salt, and borax. Four to six terraces are very distinct about Lake Mono. Some of these are traceable all the way around it; the highest is, according to Whitney, 680 feet. They are undoubtedly the remains of former lake-levels. The highest level would reach the moraines at the foot of the Sierra. Near the centre of the lake is a group of volcanic islands in a line with the group of volcanic cones on the plain to the southward. Steam and boiling water issue in many places in the rocky part of the island and in the shallow waters of that vicinity. The twenty or thirty volcanic cones on the plain vary in height from 200 to 2,700 feet above the plain. Some of them are probably recent, and retain a perfect form. Prof. Le Conte adduced evidence to show that the eruptions were-at least in part--more recent than the glaciers, and that many of the volcanoes themselves were also of later date than the Champlain epoch to which the glaciers are assigned. From his observations on Lake Mono, Prof. Le Conte concluded that its level is again rising, and that this had been going on for ten or fifteen years. He found near the margins of the lake, sheep-corral fences and old trails, submerged many feet. He also found dead sage-brush (Artemesia tridentata) and greasewood (Sarcobatis verniculatus), that were under five feet of water. Neighbouring residents estimate the rise of the lake as ten to twelve feet in ten to fifteen years. The cause is evidently an increase of rainfall, and especially of snowfall. With regard to a moving snowfield, or rather an imperfect glacier, on Mount Lyell, Prof. Le Conte finds signs that the ice is advancing.

In a paper on vowel theories in the light of recent experiments with the phonograph, Prof. Graham Bell discussed the whole subject, and gives an account of his own recent experiences. Prof. Bell formulates his research as follows :We may adopt the "fixed pitch theory," which supposes that the partial tones characteristic of vowel sounds have fixed, in. variable pitches; and the element of pitch may be considered the distinguishing feature; or we may adopt the "harmonic theory," which assumes that the partial tones are harmonics of the fundamental, varying in pitch with it ; the vowel characteristic lying in the predominance of certain harmonics. The fixed pitch theory finds much support from a consideration of the mechanism of speech. Various experiments, of which Prof. Bell exhibited a considerable number, tend to bias the mind in favour of this theory. But in a series of careful experiments with the phonautograph it was found that (I) Vowel sounds uniformly produced periodic curves, whatever pitch of voice was employed ; (2) The form of vibration was not a stable phenomenon; (3) Different vowels, sung to different pitches, often produced sensibly similar curves; (4) Different vowels sung to the same pitch yielded curves of different shapes; but the differences were not so well marked as to identify the vowels; (5) The size of the aperture seemed to influence the complexity of the tracing. Prof. Bell tried a phonautograph made with the tympanic membrane of the human ear, but obtained no different results. The general indications of the phonautograph thus favour the harmonic hypothesis. The phonograph was finally tried to help in solving this problem. Other experimenters have tested the instrument on this point. After describing their experiments and results, Prof. Bell gave the details of his own. By changing the speed of the phonograph, such words as "mean, mane, men," were altered (approximately) to "moun, moan, morn," and the reproduced ee became a faint oo. Different opinions as to these sounds are entertained by others who have experiments of a similar character, but all of the numerous researches made on this subject confirm Prof. Bell in his view that the phonograph answers the question of vowel fixity in the negative. Some very recent experiments, made by Prof. Bell and Mr. Francis Blake, conjointly, not only demonstrate that the vowel quality changes under varying speed of the phonograph cylinder's rotation, but also show the direction and nature of the change. This was shown by starting the cylinder at a given velocity, and letting it slowly come to rest. During this reduction of speed the vowelsound "ah" changed successively from "ah" to "awe," "oh," and "oo." (The same effect can be produced by gradually contracting and rounding the orifice of the lips, while, at the same time, the back of the tongue is slightly raised.) With decreasing rapidity of the cylinder, the prime tone and the partial tones'fall simultaneously in pitch. If a gradually increasing velocity was employed, the vowel-sound "ah" gradually changed to that of "ir" in "sir," and then to that of "a" in the word "man." Meanwhile, the quality of the sound became metallic. These facts favour the fixed pitch theory. Prof. Bell approves the sug. gestion of Ellis, that "what we call our vowels are not individuals-scarcely species-but rather genera, existing roughly in a speaker's intention; but at present mainly constituted artificially by the habits of reading and writing. Of the two hy. potheses it is certain that one (the harmonic) is wrong, and the other only partly right. Treating vowels as we find them-as genera of sounds instead of individuals-the most plausible theory seems to consist in what we may term the "Harmonic Fixed Pitch Theory," according to which a vowel is a musical compound composed of partial tones whose frequencies are multiples of the fundamental of the voice, the predominant partials being always those that are nearest in pitch to the resonance cavities formed in the mouth by the position of the vocal organs assumed during the utterance of the vowel. An interesting discussion followed the reading of this paper. Prof. A. M. Mayer remarked that it is exceedingly difficult to obtain uniformity of results in analysing vowel-sounds. One curious experiment made by Prof. Mayer consisted in covering the ears of a human subject with soft wax, so that they were hermetically sealed, and then applying to the top of the head an instrument which gave forth a certain note. The person thus treated heard the note one octave higher than it was actually sounded. On the whole, it must be admitted that we know very little of physiological acoustics.

The following is a list of the papers read at the meeting of the Academy :-

C. S. Peirce-On Ghosts in Diffraction Spectra; On Comparison of Wave-lengths with the Metre; On a Method of Swinging Pendulums, proposed by M. Faye; On the Errors of Pendulum Experiments; On Projections of the Sphere which still Preserve the Angles. S. H. Scudder-The Palæozoic Cockroaches. Henry Draper--Conformation, by Spectrum Photographs, of the Discovery of Oxygen in the Sun. S. Weir Mitchell-The Relation of Neuralgic Pains to Storms and the Earth's Magnetism. Joseph Le Conte-On the Extinct Volcanoes about Lake Mono, and their Relations to the Glacial Drift E. D. Cope-On the Extinct Species of the Rhinoceros, and Allied Forms of North America. E. W. Hilgard-The Loess of the Mississippi and the Aolian Hypothesis. J. E. HilgardAn Account of Geodetic Arcs determined by the Coast Survey in Relation to the Figure of the Earth; an Account of Recent Comparison of the British Imperial Standard with its Copies sent to the United States. J. E. Hilgard-Report of Progress of the International Bureau of Weights and Measures at Paris. G. K. Gilbert-On the Stability and Instability of Drainage Lines. E. C. Pickering-Eclipses of Jupiter's Satellites; two New Forms of Micrometer. C. V. Riley-The Hibernations and Migrations of Aletia argillacea (the parent of the cottonworm). Alfred M. Mayer-Description and Exhibition of a 
New Form of Heliostat. C. F. Chandler-A New Polariscopic Method for the Detection and Estimation of Dextro-glucose in the Presence of Cane'Sugar and Inverted Sugar. A. Graham BellVowel Theories considered in the Light of Recent Experiments with the Phonograph and the Phonautograph. Elias LoomisThe Winds on Mount Washington Compared with the Winds near the Level of the Sea. Henry L. Abbot-The Ignition of High Tension Fuses. Alexander Agassiz-Report on Dredgings in the Caribbean Sea by the Coast Survey Steamer Blake, Commander, John R. Bartlett, U.S.N. C. F. Chandler-On Two New Diazo Colours from Coal Tar. G. J. Brush-On a Mineral Locality in Fairfield County, Connecticut. H. A. Newton-On the Influence of Jupiter on Bodies passing near the Planet. J. S. Newberry-On the Great Silver Deposit recently Discovered in Colorado, Utah, and Nevada. Simon Newcomb -On the Recurrence of Solar Eclipses, F. A. P. BarnardReport of the Committee on Weights, Measures, and Coinage.

\section{NATIONAL WATER SUPPLY}

7 HE Society of Arts has again done useful work in bringing together a jury of experts on the question of water supply; for though the subject has engaged public attention for nearly half a century, has been investigated by Royal Commissions, and inquired into by committees appointed by scientific societies, we still find ourselves face to face with so costly and cumbersome a system of legislature, that although the country receives a rainfall which has been amply demonstrated to be far in excess of all the requirements of human consumption, manufacturing interests and purposes of canalisation, we see large districts suffering all the ills due to a polluted water-supply, whilst in other areas excessive rainfall is passing to the sea in devastating floods.

It is obvious, from a consideration of this fact, that there exists but one remedy for this state of things-the creation of a central authority, with power over the whole waterrights of the country for all purposes whatsoever; and upon this point there is a most striking unanimity of opinion in all the speakers attending the Society of Arts conference this year and last. Whether this authority should be placed over the whole of the 215 river basins of England and Wales, or whether they should be subdivided into groups, each presided over by separate bodies, is a question of detail, and it is necessarily one which allows of a very large amount of difference of opinion, varying with the special knowledge and tendencies of the individual propounding the scheme.

Sir Henry Cole last year suggested a division into seven districts, each under a local commission, assisted by a well-known engineer, together forming a united board, for the discussion of general questions.

Mr. Shelford pointed out that 158 river basins are contained in one county, and might be presided over by county boards, while only eleven rivers are situated in four or more counties, for which he considers special legislation would be necessary. Mr. De Rance would divide the country into six groups of river basins, Mr. Conder into ten, and he suggested the formation of a board similar to the Hydraulic Works Department in Italy, who at once take charge of the area and population of each province, the altitude of the ground, the volume of the rivers, and the amount of rainfall.

To elicit information as to the best means of dividing the country into separate watershed areas, having regard to the wants of the population and the geological and hydrological conditions, the Society of Arts offered for competition, at the Congress just held, a gold and three silver medals. No paper, it appears, has been judged of suffcient value to entitle the author to the gold medal, but two, of the seven papers selected for printing, have been thought worthy of silver medals, contributed by Mr. F. Toplis and Mr. J. Lucas. The former proposes that the country should be mapped out into watershed districts of one or more river basins, governed individually by a body of commissioners, assisted by competent legal and engineering advisers, with charge over all rivers, and power to acquire all existing water-works and canals, acting under the direction of a Minister of Health.

Mr. Lucas divides the country into northern, midland, and southern districts, with the idea of giving the commissioner presiding over each area a similar disposition of mountains and plains and constituent geological strata.

Other authorities propose still other subdivisions, and we cannot but think that the legislative creation of a numerous body of commissioners, in various districts, each with varying requirements and conflicting vested interests, would for the present only tend to increase the existing confusion; for, as we stated last year, quoting Dr. Child, "the bane of all local government in England is the chaos of different and often conflicting authorities, existing each for a special purpose." It is difficult to see how this state of things would be improved by the large powers proposed to $b_{2}$ given to a number of new local governing bodies. For ourselves we are more inclined to agree with Capt. Douglas Galton, that all existing information should be brought to one focus, and though this information lies scattered over many departments, the Local Government Board is the legitimate focus for it ; and that whether or no it is considered necessary that a Minister of Health be appointed, the preliminary step which can at once be taken is to place the heads of departments who hold information in official relation with the Local Government Board. The departments he specially referred to, being the Geological Survey, the Ordnance Survey, the Register-General's Department, and the Rainfall Committee.

The maps of the Ordnance Survey that would be most useful for hydrological purposes are those on the scale of six inches to the mile, published for the six northern counties, part of Flintshire, and for the neighbourhood of London; but unfortunately for those who have recognised the practical value of the maps on this scale, for economic purposes, the Directors of the Ordnance Survey have given priority of appearance to the larger 25-inch maps, which in addition to the objection found to their use, from the small area they include, do not contain the contour lines of equal level, which give to every 6-inch map the usefulness of a model. The Ordnance Survey are, however, bringing out a new issue, brought up to date, of their I-inch map of England and Wales, reduced from their 25 -inch map; this new $\mathrm{I}$-inch map has no hill-shading, which so often obscured the topography of the older editions, but in its place contains the principal contour lines. This map will form an admirable basis for tracing the watersheds and other hydrological purposes for which the published Ordnance Survey Catchment Basin Map is far too small.

The information collected by the Geological Survey, consists of geological maps of a large region on the scale of one inch to the mile, and of maps on the six-inch scale in the northern counties, coloured for the geological formation, and "stippled" for the superficial clays and sands with which they may be overlaid; sections across country on the six-inch scale, showing the thickness of the various permeable and impermeable formations; memoirs descriptive of districts, and including the more minute details of the strata, and particulars of the wellsections. On the latter head we would specially allude to the exhaustive detail of wells, given in the memoir of the London basin, by Mr. Whittaker, which has furnished so practical a basis for the useful investigations of $\mathrm{Mr}$. Lucas, who has added to them, from personal examination, the level of the underground water in the metropolitan area.

From information supplied by $\mathrm{Mr}$. De Rance to the conference, it appears that the pervious water-bearing formations occupy about 22,000 square miles, absorbing on an 